\title{
(Accepted manuscript) Argumentation as a bridge between metaphor and reasoning
}

\author{
Francesca Ervas \\ Dipartimento di Pedagogia, Psicologia, Filosofia \\ Università di Cagliari \\ Elisabetta Gola \\ Dipartimento di Pedagogia, Psicologia, Filosofia \\ Università di Cagliari \\ Maria Grazia Rossi \\ ArgLab-Institute of Philosophy of Language (IFILNova) \\ Universidade Nova de Lisboa
}

\begin{abstract}
The aim of this paper is to explore the relationship between metaphor and reasoning, by claiming that argumentation might act as a bridge between metaphor and reasoning. Firstly, the paper introduces metaphor as a framing strategy through which some relevant properties of a (generally more concrete and know) source domain are selected to understand a (generally less concrete and know) target domain. The mapping of properties from the source to the target implicitly forces the interpreter to consider the target in a specific perspective. Secondly, the paper presents metaphor as an implicit argument where some inferences can be drawn from the comparison between the source and the target domain. In particular, this paper aims to understand whether and to what extent such an argument might be linked to analogical reasoning. The paper argues that, in case of faulty analogy, this kind of argument might have the form of a quaternio terminorum, where metaphor is the middle term. Finally, the paper presents the results of an experimental study, aiming to test the effect of the linguistic nature of the middle term on the detection of such faulty analogy. The paper concludes that a wider context is needed to make sense of an analogical argument with novel metaphors, whilst in a narrow context a lexicalised metaphor might be extended and the overall argument might be interpreted as metaphoric.
\end{abstract}

\section{Keywords}

Metaphor, analogical reasoning, fallacy of equivocation, framing, lexical ambiguity. 


\section{§1. Introduction}

This paper aims to clarify the link between metaphor and reasoning, by claiming that argumentation might act as a bridge between metaphor and reasoning. Here, the term "argumentation" will be used in an intuitive sense, as covering any conveying of alleged reasons in support of conclusions that the speaker/writer wishes the hearer/reader to draw from some premises. In this intuitive sense, argumentation is strictly bound to reasoning as the activity of critically evaluating and justifying a standpoint on the basis of its grounds and warrants. From this point of view, the link between argumentation and reasoning might seem quite obvious, but the link between argumentation and metaphor is less so, even though it is fundamental - in our view - to understand why argumentation can be considered a bridge between metaphor and reasoning.

The first part of the paper will introduce metaphor as a persuasive device. The paper claims that metaphor is a framing strategy through which a (generally more abstract and less known) target domain is seen in light of a (generally more concrete and better known) source domain. Some relevant properties of the source domain are selected to understand the target domain, but in projecting such properties into the target domain, other properties remain underrated or simply hidden. The mapping of properties from the source to the target implicitly forces the interpreter to consider the target in a specific perspective.

The second part of the paper will specifically argue that metaphor is argumentative, in that it could be seen as an implicit argument where some inferences can be drawn from the comparison between the source and the target domain. In particular, this paper aims to understand whether and to what extent such an argument might be by analogy. Indeed, as noted by Richard Epstein and Carolyn Kernberger (2006: 37), "A comparison becomes reasoning by analogy when it is part of an argument: on one side of the comparison we draw a conclusion, so on the other side we should conclude the same". The paper will argue that, in case of metaphor, this kind of argument might have the form of a quaternio terminorum. Indeed, a shift in the metaphorical meaning of one term might lead to the fallacy of equivocation.

The third part of the paper will present the results of an experimental study, to understand when and to what extent metaphors play a persuasive role in argumentation, leading people to consider fallacious argument as sound. The study aims to test the effect of the linguistic nature of the middle term on the detection of the fallacy of the four terms, in particular, in cases of metaphor as the middle term. The results show that participants found arguments having lexicalised metaphors as middle terms more persuasive than arguments having literal terms as middle terms, when the conclusion of the argument is plausible. The paper argues that a wider context is needed to make sense of an analogical argument with novel metaphors, whilst in a 
narrow context a lexicalised metaphor might be extended and the overall argument might be interpreted as metaphoric.

\section{§ 2. Metaphors as persuasive strategies}

In recent decades, scholars have devoted particular attention to the role of metaphors in everyday communication and have underlined their role as useful persuasive strategies in understanding and reasoning. By reconsidering traditional approaches to this issue (Aristotle 1966; Black 1962; Hesse 1963), most of them have drawn attention to the persuasive function of metaphors (Rossi 2016; Lakoff 1992, 2014; Lakoff and Johnson 1980; Sopory and Dillard 2002; Thibodeau and Boroditsky 2011, 2013). Like other persuasive strategies (e.g., emotions and seduction), metaphors can be used to persuade, namely to promote "change in attitudes that results from the exposure in communication» (Petty and Cacioppo 1986, p. 5). Following this general definition of persuasion, it can be argued that any linguistic act of persuasion is a perlocutionary act (Austin 1962) which affects the hearer/reader's attitudes, modifying her feelings, thoughts and/or actions. As already highlighted by Marie-Odile Taillard (2000), understanding and believing can be deemed as the two main functions of communication achieved by means of persuasion.

While the role of metaphors as powerful persuasive devices is well recognised, consensus on which features affect their quality and therefore their persuasive effect is lacking (Sopory and Dillard 2002; Damerall and Kellogg 2016; Giora 2003). What is rather known is that the persuasive effect of metaphors depend on how they frame a given issue, that is how metaphors select and make salient only some characteristics and properties of an issue. Moving from the traditional framing theory, Robert Entman provides a general definition of frame:

To frame is to select some aspects of a perceived reality and make them more salient in a communicating text, in such a way as to promote a particular problem definition, causal interpretation, moral evaluation, and/or treatment recommendation for the item described (Entman 1993, p. 52).

Persuasion is strongly related to the four framing functions described by Entman: how frames can propose a new definition of a problem, diagnose causes, make moral judgments, and suggest remedies to it. In a recent paper, Christian Burgers, Elly Konijn and Gerard Steen (2016) use Entman's definition to outline figurative framing as a specific framing type, with metaphorical framing completely falling within the figurative framing type. More specifically, they have stressed two distinct elements of a frame by 
distinguishing between the linguistic packing and the conceptual content of a frame. They claim that frames work both as a framing device due to how something is said and a reasoning device due to the conceptual content of what is said (see also Rossi 2016). In this regard, previous experimental studies have found that exposure to a metaphor framing can induce substantial differences in opinion and modify people's everyday reasoning. For example, Paul Thibodeau and Lera Boroditsky $(2011,2013,2016)$ have found that people are influenced by metaphorical framing in conceptualising and reasoning about possible solutions to avert crime. The authors have shown that when crime was presented in metaphorical terms as CRIME AS A VIRUS (namely, as a virus infecting a city and plaguing it), participants in the experiments were increasingly prone to suggest institutional social reforms to deal with the problem. Instead, when crime was presented by using the metaphor CRIME AS A BEAST (namely, as a wild beast preying on a city and increasingly lurking in it), participants were increasingly prone to suggest law enforcement and punishment to deal with it.

Similar findings have also been reported from other fields, such as healthcare communication. David Hauser and Norbert Schwarz (2015) have produced evidence on the influence of ENEMY and WAR metaphors on the preventive behaviors of patients suffering from cancer: when the ENEMY and WAR framing were used, self-limiting behaviors (e.g., reduction in alcohol and red meat consumption) that reduce the risk of cancer were not favoured. This occurred because such a framing is associated more with active engagement behaviors supporting attacks against an enemy (e.g., be physically active). Interestingly, in all such cases, the persuasive effect due to metaphorical framing affects people in an implicit and often an unconscious way. In this paper we are interested in analysing precisely how and to what extent information conveyed by metaphorical framing (whether or not explicit) and therefore offering a particular perspective on an issue, alters human understanding and reasoning (see also Ervas et al. 2016).

\section{§ 3. Metaphors as argumentative devices}

When considering prototypical persuasive contexts (e.g., advertisement), it is quite obvious pointing out the role of metaphorical frames as effective communicative strategies to promote a particular perspective. In this respect, it has been claimed that metaphors are reasoning devices useful also to encourage perspectival changes on an issue (Burgers et al. 2016; Steen 2008), regardless of whether or not their influences operate at the conscious level. In this contribution we use argumentation to explore the role of metaphors in understanding and reasoning. 
Although it is known that metaphors are useful to structure and organize arguments of a message (Gentner 1982, 1989; Rossi 2016; Macagno and Zavatta, 2014; Oswald and Rihs, 2014; Wagemans 2016), a solid theoretical approach on metaphors is still missing within argumentation theory. The prevailing interpretation within argumentation theory is rather related to an interpretation of metaphor in "the context of the argumentative theory of analogy" (Perelman and Olbrechts-Tyteca 1958, p. 399; but see also Wagemans (2016) for a critical discussion of this approach; Macagno, Walton and Tindale 2017; Macagno forthcoming). Chaim Perelman and Lucie Olbrechts-Tyteca (ibidem) argue: «In the context of argumentation, at least, we cannot better describe a metaphor than by conceiving it as a condensed analogy, resulting from the fusion of an element from the phoros ${ }^{1}$ with an element from the Theme».

The similarities between metaphor and analogy have been discussed at both the theoretical and the experimental level. For example, Dedre Gentner and collaborators (2001, p. 243) have proposed, inter alia, that «metaphor is like analogy - that the basic processes of analogy are at work in metaphor». From this point of view, like analogies, metaphors also are processed as systems of relations:

When a metaphor is first encountered, both the target and base terms refer to specific concepts from different semantic domains, and the metaphor is interpreted by aligning the two representations and importing further predicates from the base to the target. One result of this mapping is that the common relational structure that forms the metaphor interpretation will increase in salience relative to nonaligned aspects of the representations. If the same base term is repeatedly aligned with different targets so as to yield the same basic interpretation, then the highlighted system may become conventionally associated with the base as an abstract metaphoric category (ivi, pp. 228-229).

Authors also discuss the differences between types of metaphors (e.g. conventional vs. novel metaphors). For this latter should be called into question different interpretation processes (see Sect. 7).

At the theoretical level, Perelman and Olbrechts-Tyteca's idea of metaphor as an implicit and condensed argument has been taken up by Steve Oswald and Alain Rins (2014). Analysing the extended metaphor "USA is an empire" contained in a political pamphlet written by the Swiss politician Oskar Feysinger, they have highlighted the role of extended metaphors as argumentative devices to build up the (1) message's convincingness and (2) speaker's perceived competence (ethos). The multiple and coherent systematic correspondences between the target (USA) and the source domain

\footnotetext{
1 Perelman and Olbrechts-Tyteca $(1958,82)$ offer the following definition of phoros: «In the ordinary course, the phoros is better known than the theme of which it should clarify the structure or establish the value, either its value as a whole or the respective value of its components».
} 
(EMPIRE) can be remarkably exploited in an argumentative way. So, in a way, novel metaphors and extended metaphors may be placed on an opposite end of a continuum $^{2}$ : in the first instance, the system of relations is less explicit or is entirely implicit, this is the reason behind the difficulty in reconstructing the metaphorical meaning (Macagno and Zavatta 2014); conversely, in the latter case, the repeated instantiations of the same metaphor make for a "complex argumentation» (Oswald and Rihs 2014, p. 146) through which reality can be perceived and interpreted. However, the close relation between analogy and metaphor is not limited to the explicit systems of relations prevailing in extended metaphors. In the next section, we will further analyse the argumentative exploitation of analogy in extended and non-extended metaphors.

\section{§ 4. Metaphor and analogical reasoning}

The distinction between metaphor and analogy is very clear if we take the classical definition of both phenomenon. That is, on one hand the idea of metaphor as a figure of speech, where one things means another, something which is similar in some respect: metaphors are instances in which words, e.g. goldmine, is referred to a concept which belongs to a different domain (e.g. encyclopedia). On the other hand analogy is a logical structure in which we can infer an unknown concept through a proportion: $A: B=C: X$. In this case there is a comparison (between $B$ and $X$ ), justified from the similarity of the relations among A-B and C-X. For example it is the relation "Breath with" among "Mammals" and "lungs" that authorizes the inference to the existence of something similar to "lungs" in "fishes" ("Fishes"-"Breath with"- X). If we consider the conceptual theory of metaphor (Lakoff and Johnson 1980), the difference between metaphor and analogy is pretty fine: an analogy can be grounded in a conceptual metaphor; a conceptual metaphor can be based on an analogy; each analogical proportion can be viewed as one of the relationships that define the conceptual metaphor mapping.

The conceptual metaphor LIFE IS A JOURNEY, for example, might have the following possible analogies:

1) The starting point : journey $=X$ : life

2) The ending point : journey $=X:$ life

3) The mean to move : journey $=X$ : life

The analogical reasoning should allow us to draw reasonably sound conclusions about

$\mathrm{X}$, through the proportion. When the mapping is conventional, we already know the words to substitute $X$, as for instance in:

4) The starting point : journey = birth : life

\footnotetext{
${ }^{2}$ See Sect. 4 and 6 for more details on the distinction between lexicalised and novel metaphors.
} 
Moreover the conceptual metaphor can suggest new (uncertain and risky) analogies, as in the following case:

5) The mean to move : journey $=X$ : life

We do not have a lexicalised concept, but we can reason about it considering the way in which the mean of transport might play a role in the target domain. This case is very frequent in scientific discovery and in explanation processes (Hesse 1963; Gentner 1982, Ervas et al. 2017).

Some examples of scientific reasoning related to discovery processes are analysed by Dedre Gentner and Michael Jeziorsky (1993). They consider analogies as evolution of metaphors: they compare alchemists, who used many metaphors in an extensive and disordered manner, and authors such as Robert Boyle (1627-1691) and Sadi Carnot (1796-1832) who instead used analogy to infer the structure of local motion and heat respectively. Carnot introduced the parallelism between «the motive power of heat and the motive power of water and establishes a simple, yet important parallel. Just as the amount of power produced by a given fall of water is limited, the power attainable from a certain transfer of heat is limited» (Gentner and Jeziorsky 1993, p. 453). He then established the correspondence between the amount of substance (water or caloric) that "falls" and the distance of the "drop" between levels. This is actually a systematic relational structure, typical of modern scientific practice. Therefore, scientific analogies are creative because they match two domains conceptually unrelated before, under the condition that relationships between them are systematic and coherent.

A similar process from a possible (nonliteral) similarity between different concepts to analogy is also described by Lynne Cameron (2003) in teacher-students interaction. Cameron discusses the example of a teacher explaining the formation process of igneous rocks; the teacher compared volcanic lava with "sticky treacle" and "runny butter", while a student suggested a third comparison with "wax". Among these three metaphors only the second one ("runny butter") preserves the structure of the source domain in the target domain. It is really an analogy, because it keeps the same "relations" within the conceptual domains: heating butter causes a change in the substance similar to what happens to heated rock. In Cameron's words: «Treacle and wax are not analogies in this sense, since treacle does not need heat to change it to a liquid, and wax, once melted, does not further change its form as it gets hotter» (Cameron 2003, p. 104). During the whole discourse, the teacher increased students' understanding by adding details that made the analogy precise (e.g. how igneous rocks came to be formed). From this point of view, the interaction around metaphors creates a series of shared ideas in the developing discourse, that gradually brings the teacher's and students' understanding closer.

In both these cases, the development of understanding (through analogies) in scientific discovery and in interactive talking-and-thinking teaching discourse, we see a process that aims to understand something that is considered at some level true 
(Gentner 1982, 1989). Each part of the proportion (or mapping) can be examined to state the degree of truth or plausibility in cases in which a right answer is not known. The analogical reasoning, in any case, is an uncertain reasoning, in which there is always an assumption of truth that is not necessarily correct. The analogy between the atom and the solar system, stated by Niels Bohr and Ernest Rutherford in 1913, for example, had been considered true until quantum mechanics offered a different model of the atom. However, even though the model has been superseded, the idea that an atom is a small, positively charged, nucleus, surrounded by electrons that travel in circular orbits around it still holds. The analogy is still valid in this respect, but it was literally false, from the very beginning, about other aspects that remained unanswered: "The orbits were continuous and could occur at any distance from the nucleus, so why was the energy given off by atoms limited to specific frequencies? What "tuned" the atoms, keeping their electrons in certain paths with certain amounts of energy? How was it that they could jump from one path to another, as from the note $A$ to $C$, but never performed a glissando in between?» (Root-Bernstein and Root-Bernstein 1999, p. 136). This shows that analogical reasoning is a type of reasoning that we trust, even if the conclusions of this kind of schema are not necessarily true, or even false. In the following sections, we will examine a specific case in which this kind of reasoning becomes fallacious, and how language use has an impact on analogy comprehension.

\section{§5. Analogical reasoning and quaternio terminorum}

When is analogical reasoning sound and when is it fallacious? Argumentation theory discusses the conditions under which a conclusion follows from true premises. To this effect, the concepts of validity and soundness are required (Walton 2005, 2010): an argument is valid if its conclusion is true whenever its premises are true, whilst an argument is sound if it is valid and all its premises are true. Validity and soundness are crucial in evaluating arguments. Nonetheless, these notions seem too tight for ordinary language in communication. Due to this reason, two weakened versions of these concepts are strength and goodness (Bonissone 1987; Borwein and Bailey 2008; Epstein and Kernberger 2006, ch. 3). We call an argument strong if its conclusion is very likely to be true, whenever its premises are true. In other words, premises provide reasons that support the probable truth of the conclusion. We call an argument weak which is not strong: a fallacy is a weak argument. An argument is good if it is strong and all its premises are plausible.

In analogical reasoning, featuring a metaphor, it might be argued that a comparison between two terms $A$ and $B$ is established, where $A$ and $B$ share some relevant properties. In metaphors with the form " $A$ is $B$ ", the speaker is neither saying 
that all the properties of $B$ correspond to the properties of $A$, nor vice-versa. For instance, when we say that "A lawyer is a shark", we are not saying that a lawyer is identical to a shark, but rather that a lawyer is similar/comparable to a shark in some respect, i.e. a set of relevant properties $X$. Based on this comparison, if $B$ has the relevant property $C$ (belonging to the set $X$ ), then we are authorised to conclude that $A$ also has the property $C$. In this perspective, given that "A shark is aggressive", as per analogy, we should conclude that "A lawyer is aggressive". The argument would then be:

$\mathrm{P} 1 \mathrm{~A}$ lawyer is a shark

P2 A shark is aggressive

C A lawyer is aggressive

In this case, we would probably be prone to accept the argument as strong, as "shark" might have the same reading in $\mathrm{P} 1$ and $\mathrm{P} 2$. The second premise makes explicit a property which was implicit in the first premise. However, in case the property $C$ is not included in the set $\mathrm{X}$, we would not be much prone to accept the argument as strong and hence would judge it as fallacious:

P1 A lawyer is a shark

P2 A shark is a fish

C A lawyer is a fish

In such a case, as noted by Giuseppe Sergioli and Claudio Ternullo (2014), there is a shift in the meaning of the middle term: the term "shark" would not be used with the same meaning in P1 and P2. In P1 it has a metaphoric meaning while in P2 a literal meaning. Therefore, the analogical reasoning could not be guaranteed and the argument would be fallacious because it would contain four terms instead of three terms. In other words, because of the shift in the meaning of the middle term, the argument has the structure of a quaternio terminorum. Quaternio terminorum (Copi et al. 2014, pp. 230-231; Smiley 1973, pp. 136-154) is a well known case of a fallacious argument based on the ambiguity of its middle term, which has different meanings in the two premises (Dunbar 2001; Fearnside and Holter 1959; Hamblin 1970; Kroeger 2005, $\S 3.1$; Quine 1960, §§ 27-31). If the middle term assumes a different meaning in each premise, then a syllogism, de facto, contains a fourth, hidden term, that causes the fallacy. However, a quaternio terminorum is not just a formal fallacy, in the sense of being simply an invalid syllogism (or a weak argument in case of ordinary language), it is better classified as a fallacy of equivocation, due to the lexical ambiguity of the middle term. 
As previously argued, analogical reasoning thrives on comparisons which are quite frequent in everyday language and play an important role in human reasoning. A fallacious analogical argument establishes a faulty analogy as its conclusion. As Ward Fearnside and William Holther argued (1959, p. 4):

Faulty analogy consists either in assuming that shared properties will continue indefinitely to be found in new members, or in assuming that it is highly probable there will be some other shared property in a class so wide that there is only a low initial probability of finding any other shared properties relevant to the purpose at hand.

Metaphors - because of their intrinsic ambiguity - are particularly likely to deceive us in the process of assessing the strength of an argument, i.e. the proper attribution of a certain analogy as its conclusion. Quaternio terminorum may appear prima facie strong and formally valid, but it is actually based upon lexical ambiguity.

\section{§ 6. Literal and metaphorical middle terms}

Which and how many properties are relevant, i.e. shared by $A$ and $B$, whenever we assert that they are analogous? Unfortunately, there is no other way to respond to this question but to check, each time a property of $A$ is taken into account, whether also $B$ has it. This process strictly depends on the linguistic nature of the middle term. Indeed, in quaternio terminorum, middle terms can have two different literal meanings, or else a non-literal meaning and a literal meaning, as in case of metaphors. Just to give an example of each condition:

Quaternio terminorum with a literal middle term:

$\mathrm{P} 1$ Barclays is a bank

$\mathrm{P} 2 \mathrm{~A}$ bank is a riverside

$\mathrm{C}$ Barclays is a riverside

Quaternio terminorum with a metaphorical middle term:

P1 Brad Pitt is a star

P2 A star is a celestial body

C Brad Pitt is a celestial body

When the different literal meanings of the middle term have no semantic relation, we run into a case of lexical ambiguity called homonymy (Frath 2001; Lyons 1977; Taylor 2003). For example, the term bank is homonymous because it has two completely different literal meanings: "financial institution" and "riverside". When the different literal meanings of the middle term have a semantic relation, we run into a case 
of polysemy: for instance, the term "cut" is polysemous because it has different (but semantically related) literal meanings in "cut the grass" and "cut the hair".

In the case of metaphorical middle terms, the meaning in a premise can be literal and the meaning in the other premise can be non-literal. The case of lexicalized metaphors is somewhat similar to polysemy, as their frequent use has brought them to a status similar to literal terms. This is why they are called "dead" metaphors. For instance, the word food has the literal meaning "something to eat", but it also the nonliteral meaning "something to think about", when it is used in "food for thought". As in the case of polysemy, the two meanings have a semantic relation represented by the shared properties of the source domain of eating and the target domain of thinking. Novel metaphors instead involve a completely new and creative use of language. The semantic relation between the literal and the non-literal meanings of a novel metaphor is not stereotypically assigned by speakers (and already classified in dictionaries), thus preserving its force and imaginative effectiveness. This is why they are called "live" metaphors.

Disambiguating a homonymous middle term would require suppressing one of its two literal meanings, namely the irrelevant one. For instance, disambiguating the homonymous word "bank" would require selecting one of its two meanings, i.e. "financial institution" or "riverside" (Gernsbacher 1990; Gernsbacher and Faust 1991). Contrary to homonyms, where the different meanings are clearly divergent, polysemous words exhibit a list of possible (related) meanings that can be selected. The meanings of a polysemous word partly overlap (Ervas 2015; Gentner, Ratterman and Forbus 1993; Gick and Holyoak 1983). However, also the literal and the non-literal meanings of a metaphorical term share some common semantic properties which allow for metaphor understanding.

Appealing to a "unified approach" to literal and non-literal usages of language, a process of modulation (lexical narrowing or broadening) has been proposed to explain the process of selection of the relevant meaning in polysemy and metaphors (Carston 2002; Recanati 2004, 2010). In the case of lexical narrowing, the concept communicated by using a term has a more restricted interpretation than the linguistically-encoded concept. For instance, in the sentence "I cut the grass", we select a more specific concept "cut" than the conventional concept encoded by the polysemous term "cut". This "ad hoc" concept is relative to the sentential context and differs from the "ad hoc" concept we pick up in the sentence "I cut my hair" (Ervas 2015). We speak of lexical broadening when the concept expressed by the usage of a term conveys a more general interpretation than the linguistically-encoded concept. For instance, a metaphorical extension is a type of broadening, where some properties of the linguistically-encoded concept are selected to understand the communicated "ad hoc" concept. For instance, to understand the sentence "Brad Pitt is a star", we select the properties of the linguistically-encoded concept "star" required to grasp the intended 
ad hoc concept, i.e. to be brilliant, unreachable, or extra-ordinary. Other irrelevant properties of the linguistically-encoded concept "star" (for instance, to be a celestial body) are suppressed (Glucksberg, Newsome and Goldvarg 2001; Rubio Fernandez 2007).

A suppression process is involved in both disambiguation and metaphor interpretation (Gernsbacher and Faust 1991). However, in the process of disambiguation of a homonym the irrelevant meaning disappears more quickly, when compared to the process of polysemy and metaphor interpretation, which requires more demanding attentional resources to suppress the corresponding literal meaning (Rubio Fernandez 2007). In homonym disambiguation, the irrelevant literal meaning has indeed no semantic relation with the contextually relevant meaning, while in metaphor interpretation the literal meaning of the source domain shares some semantic properties with the intended, non-literal meaning. Novel metaphor comprehension requires an even more demanding effort to find out the shared properties intended by the speaker and a finer knowledge of the context and its features (Glucksberg and Estes 2000; Indurkhya 2007). It has been argued that additional semantic information coming from the context may produce an advantage in metaphor interpretation, called "context availability effect" (Schwanenflugel, Harnishfeger and Stowe 1988, Glucksberg and Estes 2000). Moreover, in the case of novel metaphors, the literal meaning would not be suppressed straightforwardly; it would endure eliciting a range of communicated affective and imagistic effects (Glucksberg, Newsome and Goldvarg 2001; Gernsbacher, Keysar, Robertson and Werner 2001; Glucksberg 2003; Giora 2003; Indurkhya 2007; Rubio Fernandez 2005, 2007).

\section{§ 7. Experimenting with quaternio terminorum}

The kind of ambiguity of the middle term might influence the persuasive effect of a quaternio terminorum, where a faulty analogy is committed. Indeed, a quaternio terminorum requires a process of disambiguation to realize the existence of four terms in the logical structure: one of the meanings of the middle term has to be suppressed in order to identify the fallacy. In an experimental study on the effect of metaphor in quaternio terminorum (Ervas et al. 2015), it has been hypothesized that quaternio terminorum identification relies mainly on the nature of the middle term, and therefore on the process of disambiguation required to understand the meanings of the middle term. The empirical study tested a group of $(\mathrm{N}=40)$ adults by using a series of verbally presented arguments, having the structure of quaternio terminorum and containing either a lexical ambiguous ( $\mathrm{H}$ : homonymous or $\mathrm{P}$ : polysemous) or a metaphorical (LM: lexicalised metaphors or NM: novel metaphors) middle term. Three sets of arguments 
were presented: 1) 6 standard quaternio terminorum $\times(H, P, L M, N M)$, with true premises and false conclusion; 2) 6 strong arguments $\times(H, P, L M, N M)$ with true premises and true conclusion, where the middle term had the same meaning in both premises; 3) 6 quaternio terminorum $\times(\mathrm{H}, \mathrm{P}, \mathrm{LM}, \mathrm{DM})$ with true premises and plausible conclusion, to avoid the facilitation effect of the false conclusion and to force participants to check the connection between premises. Fillers contained 25 clearly strong arguments and 25 clearly weak arguments, to check whether participants know how to distinguish strong and weak arguments, without explicit instructions. The participants were asked to answer "yes" or "no" to the following question: "Does the conclusion follow from the premises?".

The results showed that the majority of participants were able to identify both strong arguments and standard quaternio terminorum. However, when compared with strong arguments, standard quaternio terminorum are much harder to detect. Indeed, strong arguments are easier to detect because they involve no disambiguation process, while a quaternio terminorum requires a process of disambiguation to realize the existence of four terms in the logical structure. Quaternio terminorum with plausible conclusion were even harder to detect, because the plausible conclusion forced participants to evaluate the whole argument and avoid a separate reading of the single conclusion. A significant difference $(p<.01)$ between participants missing and recognizing the fallacy was observed just in the LM condition. This seems to suggest that, in the case of arguments with plausible conclusion, lexicalised metaphors do alter participants' perception of the strength of a fallacious argument, thus making them to consider it strong.

In particular, the norming studies showed that the majority of premises with lexicalised metaphors (83\%) were perceived as true, as a direct consequence of their being lexicalized, while the majority of sentences with novel metaphors (79\%) were perceived as false (Ervas and Ledda 2014). The case of lexicalized metaphors is indeed very interesting because, as the experimental literature shows, they are processed as fast as literal meanings (Giora 2003) and participants show some difficulty in rejecting them as literally false (Glucksberg 2003). Determining either truth or falsity of premises with lexical ambiguities represents a major step towards the identification of a fallacy, such as a quaternio terminorum. It is common to judge sentences featuring lexicalised metaphors as true, relying on naïve intuitions and this phenomenon affects the global understanding of an argument. This might be the main reason why "common" lexicalised metaphors make fallacious arguments persuasive. Therefore, it is plausible that attributing truth conditions to premises featuring lexicalised metaphors as they were literal terms influenced the evaluation of the strength of the whole argument.

Novel metaphors as middle terms made the arguments patently fallacious, as the premises were perceived as false. However, the participants tended to make sense of the premises with novel metaphors and to consider them as true anyway, by resorting to 
a more creative style of reasoning. They did not directly assign naïve truth conditions as they did in case of lexicalised metaphor as middle terms. They instead added information to the premise in order to broaden its context and to make the novel metaphor understandable in the premise, thus ending up perceiving the premise as true. An example is the following quaternio terminorum:

P1 Old age is a dinner

P2 A dinner is quite long

$C$ Old age is quite long

Participants tend to explain P1 by suggesting that a dinner is at the end of the day, i.e. adding information, and in this sense it can be compared to old age, that is at the end of life. In this perspective, the conclusion might seem plausible or at least it is no longer patently false. In adjusting their comprehension of the truth conditions of the premise, participants made sense of the analogy between "old age" and "a dinner", and thus of the conclusion of the argument.

As experimental literature has shown (Schwanenflugel, Harnishfeger and Stowe 1988; Glucksberg and Estes 2000; Giora 2003), because of their unfamiliarity, a wider context is required to understand novel metaphors. The contextual information in a premise would be too narrow to produce the typical imagistic effect novel metaphors possess (Lai, Curran and Menn 2009). In argumentative contexts such as those represented by the concatenation of premises in a quaternio terminorum, the context needed to interpret novel metaphors is very narrow. As the available information in such a narrow context is not sufficient to recognize the relevant properties conveyed by the metaphor, a broader context is necessarily required. This might be the reason why participants need to resort to imagination to add information and interpret the premises with novel metaphors and make the argument meaningful. In contrast to lexicalised metaphors, novel metaphors have the positive role of enhancing imagination (Carston 2010; Carston and Wearing 2011) and recovering non-said (sometimes invented or imagined) information which elicits a new, alternative interpretation of the argument.

In case of lexicalised metaphor, instead, a narrow context provided by the argument itself might be sufficient to make sense of the analogy. For instance, in the following quaternio terminorum:

P1 Writing a thesis is a marathon

P2 A marathon is a long-distance race

$\mathrm{C}$ Writing a thesis is a long-distance race

"Marathon" is used as a lexicalised metaphor in P1 and as a literal term in P2, thus generating the fallacy of equivocation. However participants might have read the plausible conclusion as metaphorical and as the outcome of an extension of the metaphor in P1. In this perspective, P2 might simply represent an extension of the 
metaphor in P1, expliciting or even adding a property ("being a long-distance race") which might have not been considered relevant in the initial interpretation of P1, thus adjusting the "ad hoc" concept of "marathon". The possibility to extend the metaphor as middle term in P1 and to read the conclusion metaphorically is specific of reasoning with metaphors and completely missing in literal language. Such extension in the interpretation of lexicalised metaphor in the argumentative context is expedient to maintain analogical reasoning, when the conclusion is far from being patently false and might still preserve the metaphorical meaning of the first premise.

\section{§ 7. Conclusion}

The paper argued that metaphor might act as a persuasive device in argumentation and, specifically, in arguments soliciting analogical reasoning. In case of a faulty analogy, such arguments might have the structure of a quaternio terminorum, when a shift in the meaning of the middle term leads to the fallacy of equivocation. In case of lexicalised metaphors as middle term, the metaphorical reading of the middle term might be extended exploiting the narrow context of the argument, where the meaning of the middle term in the second premise is literal. Such an extension would be functional to the maintenance of the analogy already settled in the first premise in the argument and to make sense of the plausible conclusion from a metaphorical point of view. Reading the overall argument as metaphoric would be indeed a pretty reasonable alternative from participants' point of view, when compared to its evaluation as being simply fallacious, above all when the conclusion is plausible and interpretable under "other lenses".

In case of novel metaphors as middle term, instead, a wider context would be needed to make sense of the first premise itself and to perceive it as true. An imaginative route would lead the interpreter to add the relevant information required to make sense of the analogy in the first premise. Contrary to the standard conceptual theory of metaphor (Lakoff and Johnson 1980), according to which both lexicalised and novel metaphors are the "superficial" counterpart of (more or less conventional) conceptual structures, the paper argued that lexicalised and novel metaphors differ in terms of both linguistic and cognitive processing. In particular lexicalised and novel metaphors also differ in terms of communicative effects, being the first ones to be more persuasive than the latter ones in narrower contexts. The standard conceptual theory of metaphor conflates the communicative dimension of metaphor into its linguistic and cognitive dimensions, and therefore cannot explain communicative aspects which cannot be simplistically reduced solely to either the framing effect or the linguistic structure (Steen 2008, Gola and Ervas 2016). As the paper argued, the linguistic nature 
of the middle term interacts with the argumentative context and the overall persuasive effect depends not only on the framing effect given by metaphor but also to the possibility of extending it with the creation of an "ad hoc" concept (in case of lexicalised metaphors) or with recourse to imagination (in case of novel metaphors) to make sense of an analogy.

\section{Acknowledgements}

Francesca Ervas wrote sections 1 and 5-7, Elisabetta Gola wrote section 4, Maria Grazia Rossi wrote sections 2-3, but the overall paper is the result of common, shared effort. Elisabetta Gola thanks Sardinia Regional Government for the financial support (Research project: "Argomentazione e metafora. Effetti della comunicazione persuasiva nel territorio sardo", RAS, L. 7/2007).

\section{References}

Aristotle. 1966. Ars Rhetorica, ed. William David Ross. Oxford: Clarendon Press.

Austin, John Langshaw. 1962. How to Do Things with Words. The William James Lectures Delivered at Harvard University in 1955. Oxford: Clarendon Press.

Black, Max. 1962. Models and metaphors. New York: Cornell University Press.

Bonissone, Piero. 1987. Plausible Reasoning: Coping with Uncertainty in Expert Systems. In Encyclopedia of Artificial Intelligence, ed. Stuart C. Shapiro, 854-863. New York: John Wiley and Sons.

Borwein, Jonathan, and David Bailey. 2008. Mathematics by Experiment: Plausible Reasoning in the 21st Century. Wellesley (MA): AK Peters.

Burgers, Christian, Elly A. Konijn, and Gerard J. Steen. 2016. Figurative Framing: Shaping Public Discourse Through Metaphor, Hyperbole, and Irony. Communication Theory: 1-21. doi:10.1111/comt.12096.

Cameron, Lynne. 2003. Metaphor in educational discourse. London: Bloomsbury Academic.

Carston Robyn, and Wearing Catherine. 2011. Metaphor, Hyperbole and Simile: A Pragmatic Approach. Language and Cognition 3(2): 283-312. doi:10.1515/langcog.2011.010 .

Carston, Robyn. 2002. Thoughts and Utterances: The Pragmatics of Explicit Communication. Oxford: Blackwell.

Carston, Robyn. 2010. Metaphor: Ad Hoc Concepts, Literal Meaning and Mental Images. Proceedings of the Aristotelian Society 110: 295-321. doi:10.1111/j.14679264.2010.00288.x. 
Copi, Irving M., Carl Cohen, and Kenneth McMahon. 2014. Introduction to Logic. Harlow (UK): Pearson.

Damerall, Alison Whiteford, and Ronald T. Kellogg. 2016. Familiarity and Aptness in Metaphor Comprehension. American Journal of Psychology 129: 49-64. doi:10.5406/amerjpsyc.129.1.0049.

Dunbar, George. 2001. Towards a Cognitive Analysis of Polysemy, Ambiguity and Vagueness. Cognitive Linguistics 12: 1-14. doi:10.1515/cogl.12.1.1

Entman, Robert. 1993. Framing: Toward Clarification of a Fractured Paradigm. Journal of Communication 43(4): 51-58. doi:10.1111/j.1460-2466.1993.tb01304.x

Ervas, Francesca. 2015. (Becoming) Experts in Meaning Ambiguities. Humana.Mente. Journal of Philosophical Studies 28; 225-243.

Ervas, Francesca, and Antonio Ledda. 2014. Metaphors in Quaternio Terminorum Comprehension. Isonomia 4: 179-202.

Ervas, Francesca, Elisabetta Gola, Antonio Ledda, and Giuseppe Sergioli. 2015. Lexical Ambiguity in Elementary Inferences: An Experimental Study. Discipline Filosofiche 22(1): 149-172.

Ervas, Francesca, Marcello Montibeller, Maria Grazia Rossi, and Pietro Salis. 2016. Expertise and metaphors in health communication. Medicina \& Storia XVI/9-10: 91108.

Ervas, Francesca, Elisabetta Gola, and Maria Grazia Rossi. 2017. How embodied cognition still matters to metaphor studies, in Metaphor in Communication, Science and Education, ed. Francesca Ervas, Elisabetta Gola, Maria Grazia Rossi, 1-25. Berlin: De Gruyter. doi:10.1515/9783110548129-001.

Epstein, Richard, and Kernberger, Carolyn. 2006. Critical Thinking (3rd edition). Belmont: Thomson Wadsworth.

Fearnside, Ward, and William B. Holter. 1959. Fallacy: the Counterfeit of Argument. Upper Saddler River (NJ): Prentice Hall.

Frath, Pierre. 2001. Lexical Meaning, Reference and Usage. In Proceedings of the First International Workshop on Generative Approaches to the Lexicon, eds. Bouillon Pierrette and Kanzaki Kyoko, 26-28. Geneva: University of Geneva.

Gentner, Dedre. 1982. Are Scientific Analogies Metaphors?. In Metaphor: Problems and Perspectives, ed. David S. Miall, 106-132. Brighton, UK: Harvester Press.

Gentner, Dedre. 1989. The Mechanisms of Analogical Learning. In Similarity and Analogical Reasoning, eds. Vosniadou Stella and Ortony Andrew, 199-241. Cambridge, UK: Cambridge University Press.

Gentner, Dedre, and Michael Jeziorski. 1993. The Shift from Metaphor to Analogy in Western Science. In Metaphor and thought, ed. Andrew Ortony, 2nd edition, 447480. Cambridge: Cambridge University Press.

Gentner, Dedre, Brian F. Bowdle, Philip Wolff, and Consuelo Boronat. 2001. Metaphor is Like Analogy. In The Analogical Mind. Perspectives from Cognitive Science, eds. 
Dedre Gentner, Keith J. Holyoak and Boicho K. Kokinov, 199-253. Cambridge (MA): The MIT Press.

Gentner, Derdre, and Mary J. Rattermann, and Kenneth D. Forbus. 1993. The Roles of Similarity in Transfer: Separating Retrievability from Inferential Soundness. Cognitive Psychology 25 (4): 524-575. doi:10.1006/cogp.1993.1013.

Gernsbacher, Morton Ann. 1990. Language Comprehension as Structure Building. Hillsdale, NJ: Lawrence Erlbaum.

Gernsbacher, Morton Ann, and Mark Faust. 1991. The Role of Suppression in Sentence Comprehension. Advances in Psychology 77 (C): 97-128. doi:10.1016/S01664115(08)61531-9.

Gernsbacher, Morton Ann, Boaz Keysar, Rachel R. W. Robertson, and Necia K. Werner. 2001. The Role of Suppression and Enhancement in Understanding Metaphors. Journal of Memory and Language 45 (3): 433-50. doi:10.1006/jmla.2000.2782.

Gick, Mary L., and Keith J. Holyoak. 1983. Schema Induction and Analogical Transfer. Cognitive Psychology 15 (1): 1-38. doi:10.1016/0010-0285(83)90002-6.

Giora, Rachel. 2003. On our mind: Salience, Context and Figurative Language. Oxford: Oxford University Press.

Glucksberg, Sam. 2003. The Psycholinguistics of Metaphor. Trends in Cognitive Sciences 7 (2): 92-96. doi:10.1016/S1364-6613(02)00040-2.

Glucksberg, Sam, and Achary Estes. 2000. Feature Accessibility in Conceptual Combination: Effects of Context-Induced Relevance. Psychonomic Bulletin Review 7 (3): 510-515. doi:10.3758/BF03214364.

Glucksberg, Sam, Mary R. Newsome, and Yevgeniya Goldvarg. 2001. Inhibition of the Literal: Filtering Metaphor-Irrelevant Information During Metaphor Comprehension. Metaphor \& Symbol 16 (3/4): 277-298. doi:10.1207/S15327868MS1603\&4_8.

Gola, Elisabetta, and Francesca Ervas. 2016. Metaphors We Live Twice: A Communicative Approach Beyond the Conceptual View?. In Metaphor and Communication, ed. Elisabetta Gola and Francesca Ervas, 1-22. Amsterdam: John Benjamins. doi:10.1075/milcc.5.01gol.

Hamblin, Charles L. 1970. Fallacies. London: Methuen.

Hauser, David, and Norbert Schwarz. 2015. The War on Prevention: Bellicose Cancer Metaphors Hurt (Some) Prevention Intentions. Personality and Social Psychology Bulletin 41(1): 66-77. doi:10.1177/0146167214557006.

Hesse, Mary. 1963. Models and analogies in science. London: Sheed and Ward. Indurkhya, Bipin. 2007. Creativity in Interpreting Poetic Metaphors. In New Directions in Metaphor Research, ed. Takashi Kusumi, 483-501. Tokyo: Hitsuji Shobo.

Kroeger, Paul. 2005. Analyzing Grammar. An Introduction. Cambridge: Cambridge University Press. 
Lai, Vicky Tzuyin, Tim Curran, and Lise Menn. 2009. Comprehending Conventional and Novel Metaphors: An ERP Study. Brain Research 1284 (August). Netherlands: 14555. doi:10.1016/j.brainres.2009.05.088.

Lakoff, George. 1992. The Contemporary Theory of Metaphor. In Metaphor and

Thought, ed. Andrew Ortony, 202-251. Cambridge: Cambridge University Press.

Lakoff, George. 2014, The All New Don't Think of an Elephant!: Know Your Values and Frame the Debate. Chelsea Green Publishing.

Lakoff, George, and Mark Johnson. 1980. Metaphors We Live by. Chicago: University of Chicago Press.

Lyons, John. 1977. Semantics. Cambridge: Cambridge University Press.

Macagno, Fabrizio. Forthcoming. The Logic and Pragmatics of Analogical Arguments. Logique et analyse.

Macagno, Fabrizio, and Benedetta Zavatta. 2014. Reconstructing Metaphorical Meaning. Argumentation 28: 453-488. doi:10.1007/s10503-014-9329-z.

Macagno, Fabrizio, Douglas Walton, and Christopher Tindale. 2017. Analogical Arguments: Inferential Structures and Defeasibility Conditions. Argumentation 31: 221-243.

Oswald, Steve, and Alain Rihs. 2014. Metaphor as Argument: Rhetorical and Epistemic Advantages of Extended Metaphors. Argumentation 28: 133-159. doi:10.1007/s10503-013-9304-0.

Petty, Richard, and John Cacioppo. 1986. Communication and Persuasion. Central and Peripheral Routes to Attitude Change. Berlin: Springer.

Perelman, Chaim, and Lucie Olbrechts-Tyteca. 1958. The New Rhetoric: A Treatise on Argumentation. Paris: University of Notre Dame Press, trad. 1973.

Quine, Willard Van Orman. 1960. Word and Object. Cambridge: The MIT Press.

Recanati, François. 2004. Literal Meaning. Cambridge: Cambridge University Press.

Recanati, François. 2010. Truth-Conditional Pragmatics. Oxford: Oxford University Press.

Root-Bernstein, Robert S., and Michele M. Root-Bernstein. 1999. Sparks of Genius: The Thirteen Thinking Tools of the World's Most Creative People. New York: Houghton Mifflin.

Rossi, Maria Grazia. 2016. Metaphors for patient education: a pragmatic-argumentative approach applying to the case of diabetes care. Rivista Italiana di Filosofia del Linguaggio 10(2): 34-48. doi: 10.4396/20161205

Rubio Fernandez, Paula. 2005. Pragmatic Processes and Cognitive Mechanisms in Lexical Interpretation: The On-line Construction of Concepts, PhD thesis. University of Cambridge.

Rubio Fernández, Paula. 2007. Suppression in Metaphor Interpretation: Differences between Meaning Selection and Meaning Construction. Journal of Semantics 24(4): 345-371. doi:10.1093/jos/ffm006. 
Rumelhart, David E. 1993. Some Problems with the Notion of Literal Meanings. In Metaphor and thought, ed. Andrew Ortony, 298-312. Cambridge: Cambridge University Press.

Schwanenflugel, Paula J., Katherine K. Harnishfeger, and Randall W. Stowe. 1988. Context Availability and Lexical Decisions for Abstract and Concrete Words. Journal of Memory and Language 27(5): 499-520. doi:10.1016/0749-596X(88)90022-8.

Sergioli, Giuseppe, and Claudio Ternullo. 2014. Fallacious Analogical Reasoning and the Metaphoric Fallacy to a Deductive Inference (MFDI). Isonomia 4: 159-178.

Smiley, Timothy. 1973. What is a Syllogism? Journal of Philosophical Logic 2: 136-154. Sopory, Pradeep, and James Price Dillard. 2002. The Persuasive Effects of Metaphor a Meta-Analysis. Human Communication Research 28: 382-419. doi:10.1093/hcr/28.3.382.

Steen, Gerard J. 2008., The Paradox of Metaphor: Why We Need a Three-dimensional Model for Metaphor. Metaphor \& Symbol 23(4): 213-241. doi:10.1080/10926480802426753.

Taillard, Marie-Odile. 2000. Persuasive Communication: The Case of Marketing. Working Papers in Linguistics 12: 145-174.

Taylor, John. 2003. Linguistic Categorization. Oxford: Oxford University Press.

Thibodeau, Paul H, and Lera Boroditsky. 2011. Metaphors We Think With: The Role of Metaphor in Reasoning. PloS one 6. e16782. doi:10.1371/journal.pone.0016782.

Thibodeau, Paul H, and Lera Boroditsky. 2013. Natural language metaphors covertly influence reasoning. PloS one 8. e52961. doi:10.1371/journal.pone.0052961.

Thibodeau, Paul H. 2016. Extended Metaphors Are the Home Runs of Persuasion: Don't Fumble the Phrase. Metaphor \& Symbol 31(2): 53-72. doi:10.1080/10926488.2016.1150756.

Wagemans, Jean. 2016. Analysing Metaphor in Argumentative Discourse. Rivista italiana di filosofia del linguaggio 2: 79-94.

Walton, Douglas N. 2005. Fundamentals of Critical Argument. Cambridge: Cambridge University Press.

Walton, Douglas N. 2010. Why Fallacies Appear to be Better Arguments Than They Are. Informal Logic 30(2): 159-184. 